\title{
Arsenic trioxide induces p53-dependent apoptotic signals in myeloma cells with SiRNA-silenced p53: MAP kinase pathway is preferentially activated in cells expressing inactivated p53
}

\author{
FATIH KIRCELLI, CAGLA AKAY and YAIR GAZITT \\ The University of Texas Health Science Center, San Antonio, TX 78284, USA
}

Received October 26, 2006; Accepted December 1, 2006

\begin{abstract}
Mutations in p53 are the most common genetic abnormality in cancers. Arsenic trioxide (ATO) is an effective chemotherapeutic agent for the treatment of acute promyelocytic leukemia (APL) and is being tested in phase II studies in various types of cancers. We have shown that ATO is a potent inducer of apoptosis in multiple myeloma cells, engaging primarily the intrinsic apoptotic pathway in cells expressing w.t. p53 and the extrinsic apoptotic pathway in cells expressing mutant $\mathrm{p} 53$. To further establish the differential apoptotic signals of ATO in relation to p53 functional status we studied the activation of the intrinsic and the extrinsic apoptotic pathways in IM9 myeloma cells expressing w.t. p53 following silencing of p53 and p21 with the corresponding SiRNAs-GFP constructs. In untransfected cells or in cells transfected with GFP-empty vector construct we observed weak apoptosis concomitant with mild depolarization of mitochondrial membrane, depletion of reduced glutathione and release of cytochrome c. Following silencing of p53 or p21 we observed extensive apoptosis concomitant with extensive depolarization of mitochondrial membrane and depletion of reduced glutathione. We also observed in these cells activation of the extrinsic apoptotic pathway through upregulation of APO2/TRAIL and APO2/TRAIL-R2, activation of caspase 8, degradation of FLIP-L and release of apoptosis inducing factors from mitochondria, instead of cytochrome $\mathrm{c}$. In addition, we observed marked activation of the MAP kinase pathway and dephosphorylation of Akt in p53 or p21 silenced cells. Hence, silencing of p53 or p21 in IM9 myeloma cells results in diversion of apoptosis to the extrinsic pathway and sensitization of myeloma cells to ATO.
\end{abstract}

Correspondence to: Dr Yair Gazitt, Department of Medicine/ Hematology, University of Texas Health Science Center, 7703 Floyd Curl Drive, San Antonio, TX 78284, USA

E-mail: gazitt@uthscsa.edu

Key words: SiRNA-p53, arsenic trioxide, apoptosis

\section{Introduction}

Mutations in the tumor-suppressor p53 gene are the most common genetic abnormality in human cancers and constitute one of the major causes for drug resistance. The tumor suppressor protein, p53 has a crucial role in a wide range of cellular functions by modulating transformation, regulation of cell growth, DNA synthesis and repair, differentiation and apoptosis (1-6). These p53-mediated cellular responses depend on the type of stress and individual cell characteristics. It has also been shown in animal models that induction of apoptosis is the most conserved function of p53 and is important for tumor suppression. Studies to understand the effect of the mutations in the p53 gene on development of cancer have shown that p53-mediated apoptosis occurs through a combination of mechanisms which include pathways that are both dependent and independent of alterations in gene expression and these pathways are combined to amplify the apoptotic response $(7,8)$. p53 protein can induce apoptosis by facilitating the translocation of Bax from the cytosol to the mitochondria resulting in the release of cytochrome $\mathrm{c}$ and activation of caspase-9 through Apaf-1 and the apoptosome $(7,9)$. p53 can also upregulate the proapoptotic protein, supramolecular activating complex (SMAC/DIABLO) to induce indirect activation of caspase- 3 and apoptosis through its binding of anti-apoptotic proteins such as XIAP and cIAP-1 which are capable of binding caspase-3 or caspase-9 (10-14). Alternatively, p53 protein can upregulate the expression of Bcl-2 interacting domain protein (BID) which upon activation heterodimerizes with Bax on mitochondrial membranes to facilitate apoptosis and thereby actually links the extrinsic and intrinsic apoptotic pathways $(15,16)$.

Arsenic trioxide (ATO) is an effective chemotherapeutic agent for the treatment of acute promyelocytic leukemia (APL) $(17,18)$. ATO has been shown to induce apoptosis and differentiation of APL cells in APL patients with little toxicity to patients. This is achieved primarily through downregulation of the PML-RAR $\alpha$ fusion protein derived from the $t(15: 17)$ translocation in these patients similar to the effect of all-trans retinoic acid (17). ATO is also a potent inducer of apoptosis in a number of other cell types which lack the PML-RAR $\alpha$ fusion protein, including multiple myeloma cells and solid tumors (19-31). The exact mechanism of ATO-induced apoptosis in these cells is not yet clear. 
Several mechanisms were proposed including mitochondrial damage (16-28), activation of histone deacetylase (29), activation of caspase- 9 or caspase- $8(19,21,25,32)$, direct effect on mitochondrial membrane permeability pore (33), depletion of reduced glutathione (34-36) and production of superoxides (37-42). It has also been reported that ATO blocks cells in the G1 phase of the cell cycle (22) whereas other reports demonstrated blocking of cell cycle at the G2/M phase $(22,43)$.

The different members of the super family of mitogenactivated protein (MAP) kinases participate in signaling which regulates important biologic activities. Three major groups of MAP kinases exist: the p38 MAP kinase family, the extracellular signal-regulated kinase (Erk) family, and the c-Jun $\mathrm{NH}_{2}$-terminal kinase (JNK) kinase family (44). MAP kinase signaling cascades are activated by a variety of different cellular stimuli and mediate diverse responses that regulate normal and malignant hematopoiesis (44). The Erk pathway is activated in response to several cytokines and growth factors, and primarily mediates mitogenic and anti-apoptotic signals. Members of the p38 family of MAP kinases share redundant regulatory function in stress stimuli and are also involved in the synthesis of cytokines and growth factors and downstream signaling cascade mediated by cytokines and growth factors. Other functions shared by the MAP kinases family are regulation of apoptosis, cell-cycle arrest and cell differentiation (44). In this regard, several reports suggest that the MAP kinase pathway (45), and Erk and JNK (46) pathways are activated by ATO. However, the role of p53 was not reported for myeloma cells.

Mitochondria constitute the primary target for apoptosis through the release of proapoptotic proteins, in addition to caspases. Several apoptotic signals converge in mitochondria to induce mitochondrial membrane depolarization which is blocked by the Bcl-2 family of anti-apoptotic proteins (47). Mitochondrial membrane depolarization can occur as a result of primary caspase activation (e.g. caspase-8) or in a caspaseindependent pathway (48). In caspase-dependent apoptosis, MM depolarization leads to the release of cytochrome $\mathrm{c}$ which in turn initiates the proteolytic maturation of caspases within the apoptosome, the complex of cytochrome c, Apaf-1, CARD, caspase-9 and ATP (49). In the caspase-independent pathway death effectors such as apoptosis inducing factors (AIFs) can be released from the mitochondria and induce apoptosis with or without caspase activation (50). It has also been reported that AIF released from mitochondria translocates to the nucleus and binds directly to chromatin and induces chromatin condensation and partial DNA degradation (51-53). In addition to its proapoptotic activity, AIF might play an important role in redox activity through its enzymatic NADHlike activity (54).

We have previously shown that ATO induces apoptosis in myeloma cells in two different mechanisms depending on p53 status in the cells $(41,55)$. In myeloma cells expressing mutant p53 phenotype, ATO induces G2/M cell cycle arrest and apoptosis primarily through the extrinsic apoptotic pathway by activation of BID; early depolarization of mitochondrial membrane and release of AIF from mitochondria, which then translocates to the nucleus to initiate apoptosis. In contrast, cells expressing w.t. p53 were less sensitive to ATO, and
ATO arrested the cells at G1 phase of the cell cycle through activation of p21 with mild depolarization of mitochondrial membrane, release of cytochrome $\mathrm{c}$ and the activation of caspase- 9 and caspase- 3 and thus engaging primarily the intrinsic mitochondrial pathway. However, one could argue that other characteristics of myeloma cells expressing w.t. or mutant p53 may have contributed to the observed differential effect of ATO on myeloma cells. For example, one could argue that different cell lines have different rates of ATO uptake through the previously described ATO transporter (56). We therefore studied the effect of ATO on IM9 cells expressing w.t. p53 transfected with GFP expressing vector or with GFP vector containing SiRNA for $\mathrm{p} 53$ or $\mathrm{p} 21$. We compared the effect of ATO in these cells on cell cycle, induction of APO2/TRAIL and APO2/TRAIL receptor-2, mitochondrial membrane depolarization, activation of MAP kinase pathway, activation of caspase-8, degradation of FLIP and release of AIFs from mitochondria to the cytosol. Our results support our previously proposed model for p53-dependent ATO-induced apoptosis in multiple myeloma $(41,55,57)$. Preliminary results from this study were presented at the 2005 Annual AACR meeting (Kircelli F et al, abs. 1761, 2005).

\section{Materials and methods}

Cell line and culture techniques. IM9 cell line was derived from a myeloma patient and in some reports it is considered a B-lymphoblastoid cell line rather than a myeloma cell line. IM9 cells express w.t. and were obtained from ATTCC (55). U266 myeloma cell line expressing mutated p53 (55) was also obtained from ATCC. Culture conditions for these cell lines were described previously (55). To induce apoptosis cells were treated with arsenic trioxide (ATO, Cell Therapeutics Inc., Seattle, WA). ATO was added at concentrations of $0-4 \mu \mathrm{M}$ at the time points indicated.

Detection of apoptosis. Apoptosis was determined by staining of exposed phosphatidylserine residues on apoptotic cells with Annexin V-FITC (BioVision, Palo Alto, CA) as recommended by the manufacturer. Stained cells were analyzed by flow cytometry (FACSCalibur, BDIS, San Jose, CA). Quantitation of apoptosis was performed by the CellQuest program. Twenty-thousand cells were analyzed (55).

Cell cycle analysis. The effect of ATO on cell cycle was determined by staining of IM9 cells with propidium iodide (PI) as described before (55). Stained cells were analyzed by flow cytometry (FACSCalibur, BDIS) using ModFit software (BDIS). Twenty-thousand cells were analyzed.

Determination of mitochondrial membrane depolarization. Tetramethylrhodamine ethyl ester (TMRE; Molecular Probes, Eugene, OR) was used to detect mitochondrial membrane depolarization as described before (41). Briefly, cells $\left(2 \times 10^{5} / \mathrm{ml}\right)$ were cultured at $37^{\circ} \mathrm{C}$ and ATO was added at various concentrations at the time points indicated for each experiment. For measurement of MM depolarization, cells were harvested into FACS-buffer (PBS + 1\% BSA) and TMRE (final concentration of $800 \mathrm{nM}$ ) was added and cells were further cultured for $40 \mathrm{~min}$ at $37^{\circ} \mathrm{C}$. Cells were then washed with 
FACS-buffer and TMRE staining was determined by flow cytometry as described before (41). Quantitation of the extent of mitochondrial membrane depolarization was performed by measurement of the left shift of TMRE fluorescence in cells with depolarized mitochondria. Results were analyzed by CellQuest software (BD Biosciences). Twenty-thousand cells were routinely analyzed.

Determination of intracellular reduced glutathione. Monochlorobimane ( $\mathrm{mBCl}$, Molecular Probes, Eugene, OR) was used to detect reduced glutathione (GSH). $\mathrm{mBCl}$ is a thiolreactive, membrane-permeable probe that fluoresces upon excitation at $405 \mathrm{~nm}$. Although $\mathrm{mBCl}$ reacts with all free thiol groups, it preferentially forms adducts with GSH in a reaction catalyzed by the enzyme glutathione-S-transferase $(63,64)$. Briefly, cells $\left(2 \times 10^{5} / \mathrm{ml}\right)$ were cultured at $37^{\circ} \mathrm{C}$ and ATO was then added at various concentrations at the time points indicated for each experiment. For measurement of reduced GSH, cells were harvested (floating and adherent), washed and resuspended in FACS-buffer (PBS + 1\% BSA). $\mathrm{mBCl}$ (dissolved in DMSO) was added at a final concentration of $200 \mu \mathrm{M}$ and cells were incubated at $37^{\circ} \mathrm{C}$ for $20 \mathrm{~min}$. Cells were then washed with FACS-buffer and $\mathrm{mBCl}$ fluorescence was determined by flow cytometry. Decrease in reduced glutathione was measured by the extent of the left shift of $\mathrm{mBCl}$ fluorescence peak using the FACSAria flow cytometer (Becton-Dickinson, Mt. View, CA). Results were quantitated by FACSDiva software (BD Biosciences, Mt. View, CA). Twenty-thousand cells were analyzed.

Determination of p-jun, p-Erk, PTEN, GADD45 and p21 by Western immunoblotting. Cells were cultured as described above with $4 \mu \mathrm{M}$ ATO for $16 \mathrm{~h}$ and aliquots of $5-10 \times 10^{6}$ cells were washed twice with PBS and 50-100 $\mu \mathrm{g}$ of total cellular protein was separated by SDS-PAGE (55). Gel electrophoresis, immunoblotting, detection and quantification of protein bands were performed as previously described (55). Mouse monoclonal antibodies to p-c-jun (mouse, KM-1), p-Erk (mouse, clone E4), GADD45 (mouse), p21 (mouse) and p-Akt1/2/3 (rabbit; ser 475) were from Santa Cruz Biotechnology, Inc. (Santa Cruz, CA). Rabbit anti-PTEN was from Cell Signaling Technologies, Beverly, MA. Proteins were identified according to their migration on the blot. For loading controls, membranes were stripped and reprobed using antiß-actin antibody (Clone AC-15; Sigma, St. Louis, MO).

Determination of release of cytochrome c and AIF from mitochondria to the cytosol by Western immunoblotting. Cells were cultured with $4 \mu \mathrm{M}$ ATO for $16 \mathrm{~h}$ at $37^{\circ} \mathrm{C}$ and $5-10 \times 10^{6}$ cells were washed twice with PBS and the cytosolic fraction was prepared by resuspending the cell pellet in mitochondria/ cytosol buffer (BioVision, Palo Alto, CA) and passing the cell suspension through a syringe with a 22-gauge needle several times on ice. Cell homogenate was centrifuged at $10,000 \mathrm{x} \mathrm{g}$ for $10 \mathrm{~min}$ at $4^{\circ} \mathrm{C}$ to obtain the cytosolic fraction (41). For SDS-PAGE, 50-100 $\mu \mathrm{g}$ of protein was loaded onto each lane. Gel electrophoresis, immunoblotting, detection and quantification of protein bands were performed as previously described (55). Rabbit polyclonal antibody to cytochrome c (Clone H-104) and mouse monoclonal antibody to AIF
(Clone E-1) were from Santa Cruz Biotechnology, Inc. Mouse monoclonal antibody to p21 (Clone Ab-1) was from Oncogene (San Diego, CA). Cytosolic B-actin was used for loading control after stripping and reprobing.

Silencing p53 and p21 in IM9 myeloma cells expressing w.t. $p 53$. We first optimized the transfection procedure to reach $40-50 \%$ transfection of the corresponding SiRNA. We used a GFP expression plasmid containing a downstream SiRNA to p21 or p53 on a backbone of psiRNA-h7SKgz (InvivoGen, San Diego, CA). As a control, we used plasmid containing the GFP expression gene with no SiRNA (empty vector). For transfection we used the AMAXA nucleoporator. The extent of nucleoporation was quantitated by flow cytometry using GFP as a surrogate marker for expression of SiRNA. The amount of plasmid DNA, the transfection solution and the nucleoporation program were optimized for IM9 cells. Optimal nucleoporation of p21 and p53 SiRNA was obtained using 50-60 $\mu \mathrm{g}$ of plasmid DNA. Following nucleoporation, cells were washed and cultured for $4 \mathrm{~h}$ in RPMI-1640 with $10 \%$ FCS. At $4 \mathrm{~h}$, close to maximal expression of GFP was observed. In all experiments, cell sorting of $\mathrm{GFP}^{+}$cells was performed, using the FACSAria flow sorter (Becton-Dickinson) resulting with $>90 \% \mathrm{GFP}^{+}$cells.

Determination of APO2/TRAIL and APO2/TRAIL receptor-2 by immunofluorescence staining. Cells were cultured with $4 \mu \mathrm{M}$ of ATO following transfection with GFP or SiRNA for p53 as described above. Cultures were harvested after $16 \mathrm{~h}$ of treatment with ATO. Only viable cells were gated (by light scatter). Cells $\left(5 \times 10^{5}\right)$ were used for indirect immunofluorescence staining for surface expression of APO2/TRAIL and APO2/TRAIL receptor-2 as described before (58). APO2/ -TRAIL receptor-2 antibody was a gift from Immunex Corp. (Seattle, WA). APO2/TRAIL antibodies were from R\&D Systems (Minneapolis, MN). Secondary antibodies were from APC conjugates, Jackson Immunochemicals, Raritan, NJ. Appropriate immunoglobulin isotype matched controls were used for each antibody. Stained cells were analyzed by flow cytometry (FACSCalibur, BDIS). Quantitation was performed by CellQuest software (BD Biosciences). Twenty-thousand cells were analyzed.

\section{Results}

Effect of silencing of p53 and p21 on ATO-induced apoptosis in IM9 cells. In order to independently confirm the role of p53 in ATO-induced apoptosis we used SiRNA constructs to block p53 and p21 expression in IM9 myeloma cell line expressing w.t. p53. We first optimized the transfection procedure to reach $40-50 \%$ transfection of the corresponding SiRNA. We used a GFP expression plasmid containing SiRNA to p21 or p53 and as a control we used plasmid containing the GFP expression gene with no SiRNA (empty vector). For transfection, we used the AMAXA nucleoporator. The extent of nucleoporation was quantitated by flow cytometry using GFP as a surrogate marker for expression of SiRNA. The amount of plasmid DNA the transfection solution and the nucleoporation program were optimized for IM9 cells with optimal nucleoporation of p21 and p53 SiRNA obtained at 
$\mathbf{A}$

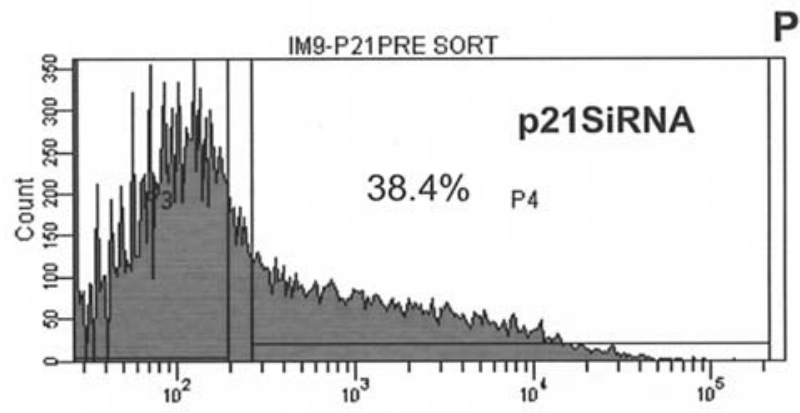

PRE SORT

FITC-A



POST SORT



FITC-A

IM9-P53 POS

B

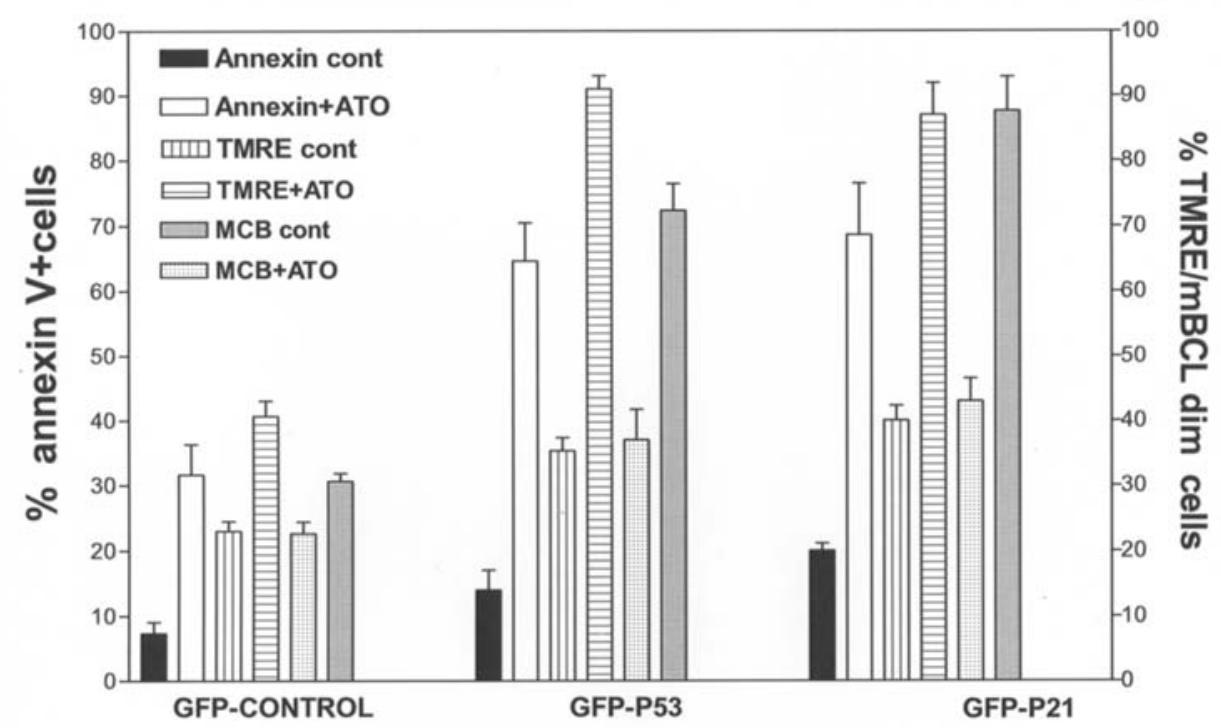

Figure 1. (A) Transfection of p53 and p21 SiRNA into IM9 cells. IM9 cells, expressing w.t. p53 were transfected with 50-60 $\mu$ g of plasmid DNA of the corresponding SiRNAs and cultured for $4 \mathrm{~h}$ to allow expression of SiRNA. Nucleoporation was performed by the AMAXA Nucleoporator and quantitation of the extent of nucleoporation was determined by flow cytometry by measuring \% cells expressing GFP. Twenty-thousand cells were analyzed. Five-million cells were transfected in each cuvette. A reproducible transfection rate of $\sim 40 \%$ was observed routinely (upper panel). In some experiments, SiRNA-transfected cells were further sorted (FACSAria, Becton-Dickinson) for $\mathrm{GFP}^{+}$cells resulting with $>90 \% \mathrm{GFP}^{+}$cells. An example is shown in A, lower panel. (B) Effect of silencing of p53 or p21 on ATO-induced apoptosis and MM depolarization and depletion of reduced glutathione in IM9 cells. IM9 cells were transfected with the corresponding SiRNAs and cultured for $4 \mathrm{~h}$ to allow expression of SiRNA. Cells were then treated with $4 \mu \mathrm{M}$ ATO for $16 \mathrm{~h}$ and then assayed for apoptosis by the Annexin V method, for MM depolarization by staining with TMRE and for the levels of reduced glutathione by Monochlorobimane (mBCl). Results were quantitated by flow cytometry. Twenty-thousand cells were analyzed. The results from 3 different experiments are shown. Bars represent \pm SD. Control-GFP-empty vector; GFP-p53-SiRNAp53; GFP-SiRNA-p21. For further details see Materials and methods.

50-60 $\mu \mathrm{g}$ of plasmid DNA. Following nucleoporation, cells were washed and cultured for $4 \mathrm{~h}$ in RPMI-1640 with $10 \%$ FCS. At $4 \mathrm{~h}$, close to maximal expression of GFP was observed. The results are depicted in Fig. 1A, upper panel. Close to $40 \%$ of the cells expressed GFP which indirectly serves as a measure for expression of the corresponding SiRNAs. In some experiments, cell sorting of $\mathrm{GFP}^{+}$cells was performed using the FACSAria flow cytometer (BD) resulting with $>90 \%$ $\mathrm{GFP}^{+}$cells. These sorted cells were used to detect changes in the levels of proapoptotic proteins (Fig. 1A, lower panel).
Effect of silencing of p53 or p21 on ATO-induced apoptosis and depolarization of mitochondrial membrane in IM9 cells. In order to verify silencing of p21 and p53, IM9 cells were transfected with SiRNA for p21 and p53 and cultured for $4 \mathrm{~h}$ to allow optimal expression of SiRNA and downregulation of the corresponding proteins. Cells were then treated with $4 \mu \mathrm{M}$ of ATO for $16 \mathrm{~h}$. Total cellular proteins were then extracted and proteins resolved on SDS-PAGE, transferred onto PVDnylon membrane and blotted for p21 and p53. We confirmed reduction in $\mathrm{p} 21$ and $\mathrm{p} 53$ protein following transfection of 


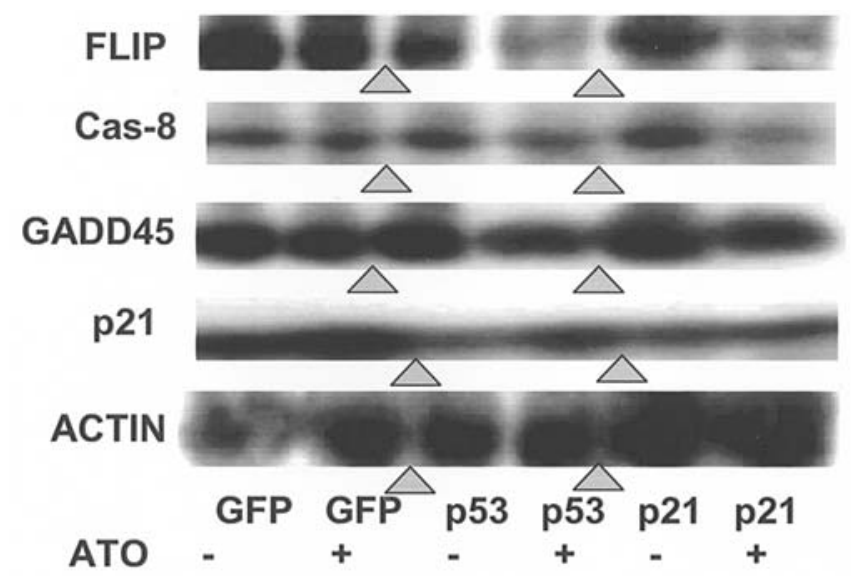

Figure 2. Effect of silencing of p21 or p53 on ATO-induced activation of procaspase-8, degradation of FLIP-L and stimulation of p21 and GADD45 in $\mathrm{GFP}^{+}$-sorted, ATO-treated IM9 cells. IM9 cells were nucleoporated and further cultured for $4 \mathrm{~h}$ to allow expression of SiRNAs. Cells were sorted for $\mathrm{GFP}^{+}$cells $(>90 \%)$ and sorted cells were then treated for $16 \mathrm{~h}$ with $4 \mu \mathrm{M}$ of ATO and cellular proteins were extracted and resolved on SDS-PAGE. Fifty $\mu \mathrm{g}$ of protein was loaded onto each lane. Proteins were transferred to a PVD nylon membrane and probed for FLIP-L, procaspase-8, p21, GADD45. Representative results from 1 of 3 experiments are shown. For loading controls, membranes were stripped and reprobed for B-actin. As predicted, ATO-induced activation of procaspase- 8 and degradation of FLIP-L were markedly enhanced in cells transfected with SiRNA to p21 or p53. Similarly, stimulation of GADD45 and p21 by ATO was markedly decreased in SiRNA-transfected cells compared to GFP-transfected cells (empty vector control).

the corresponding SiRNAs. Results for p21 are depicted in Fig. 2. Reduction $(\sim 65 \%)$ of p21 was observed in p53 and p21 SiRNA transfected cell (without ATO). Similar depletion was observed for p53 (data not shown).

We first compared the effect of ATO on IM9 cells transfected with GFP (control, empty vector), GFP-p21 and GFP-p53 SiRNA plasmids as for apoptosis, mitochondrial membrane depolarization and the levels of reduced glutathione by flow cytometry. Cells were treated with $4 \mu \mathrm{M}$ of ATO for $16 \mathrm{~h}$. The combined results from 3 experiments are depicted in Fig. 1B. Apoptosis (determined by Annexin V) was $>2$-fold higher (30-66\%) in cells transfected with p21 or p53 SiRNA compared to empty vector (GFP only) which by itself did not result with measurable apoptosis. Similarly, depolarization of MM (determined by TMRE) was $>2$-fold higher (40-84\%) in cells transfected with p21 or p53-SiRNA. Silencing of p53 or p21 resulted also in $\sim 2$-fold decrease in the levels of reduced glutathione (determined by $\mathrm{mBCL}$ ) compared to GFP-empty vector control cells in response to ATO (Fig. 1B).

Effect of silencing of p53 or p21 on ATO-induced activation of the extrinsic apoptotic pathway and cell cycle regulatory proteins in IM9 cells. To further investigate the effect of silencing of p53 or p21 on ATO-induced apoptosis we tested, by Western immunoblotting, the effect of ATO on the levels of GADD45 and p21 (downstream effectors of p53); activation of procaspase- 8 and FLIP. IM9 cells were transfected with SiRNA for p21 and p53 and cultured for $4 \mathrm{~h}$ to allow optimal expression of SiRNA and downregulation of the corresponding proteins. Cells were then treated with $4 \mu \mathrm{M}$ of ATO for $16 \mathrm{~h}$.



Figure 3. Effect of silencing of p21 or p53 on ATO-induced release of cytochrome $\mathrm{c}$ and AIF from mitochondria in $\mathrm{GFP}^{+}$-sorted IM9 cells. IM9 cells were nucleoporated and further cultured for $4 \mathrm{~h}$ to allow expression of SiRNAs. Cells were sorted for $\mathrm{GFP}^{+}$cells $(>90 \%)$ and sorted cells were then treated for $16 \mathrm{~h}$ with $4 \mu \mathrm{M}$ of ATO and cytosolic proteins were extracted and resolved on SDS-PAGE (41). Fifty $\mu \mathrm{g}$ of protein were loaded onto each lane. Proteins were transferred to a PVD nylon membrane and probed for cytochrome c and AIF. For loading controls, membranes were stripped and reprobed for $\beta$-actin. One representative experiment of 3 is shown. As expected, cytochrome c release was decreased, whereas AIF release from mitochondria was increased in p21 and p53 SiRNA-transfected cells compared to GFP-control cells

Total cellular proteins were extracted and resolved on SDSPAGE, transferred onto PVD-nylon membrane and blotted for $\mathrm{p} 21$ and $\mathrm{p} 53$. The results from a representative experiment are shown in Fig. 2. As expected, we observed a decrease in p21 and GADD45 in SiRNA transfected IM9 cells compared to GFP (empty vector)-transfected cells, following treatment with ATO. Similarly, enhanced activation of caspase- 8 and degradation of FLIP-L was observed in cells transfected with p53 or p21 SiRNAs compared to GFP only (control plasmid) suggesting a shift to the extrinsic apoptotic pathway (Fig. 2).

We tested the effect of silencing of p53 or p 21 on release of mitochondrial proapoptotic proteins. Silencing of p53 or p21 resulted also in the release of AIF from mitochondria to the cytosol, suggesting also a shift to the extrinsic apoptotic pathway. IM9 cells were transfected with SiRNA for p21 and p53 and cultured for $4 \mathrm{~h}$ to allow optimal expression of SiRNA and downregulation of the corresponding proteins. Cells were then treated with $4 \mu \mathrm{M}$ of ATO for $16 \mathrm{~h}$. Cytosolic proteins were then isolated and resolved on SDS-PAGE, transferred onto PVD-nylon membrane and blotted for $\mathrm{p} 21$ and p53 (Fig. 3). In agreement with this interpretation, we observed a decrease in the release of cytochrome $\mathrm{c}$ from mitochondria to the cytosol, in cells transfected with SiRNA to $\mathrm{p} 53$ or $\mathrm{p} 21$ compared to cells transfected with empty vector (Fig. 3). These results, taken together suggest that silencing of $\mathrm{p} 21$ or $\mathrm{p} 53$ result in sensitization of IM9 cells to apoptosis as a result of diverting ATO apoptotic pathway from the intrinsic to the extrinsic pathway.

Effect of silencing of 553 or p21 on the activation of the MAP kinase pathway. It has been shown before that the MAP kinase pathway is activated by ATO in various cell types; however the role of p53 in this pathway in myeloma cells was not studied $(45,46)$. We therefore studied in detail the effect of ATO in myeloma cells expressing w.t. vs mutant p53 and in IM9 cells transfected with SiRNA for p53 or p21. 


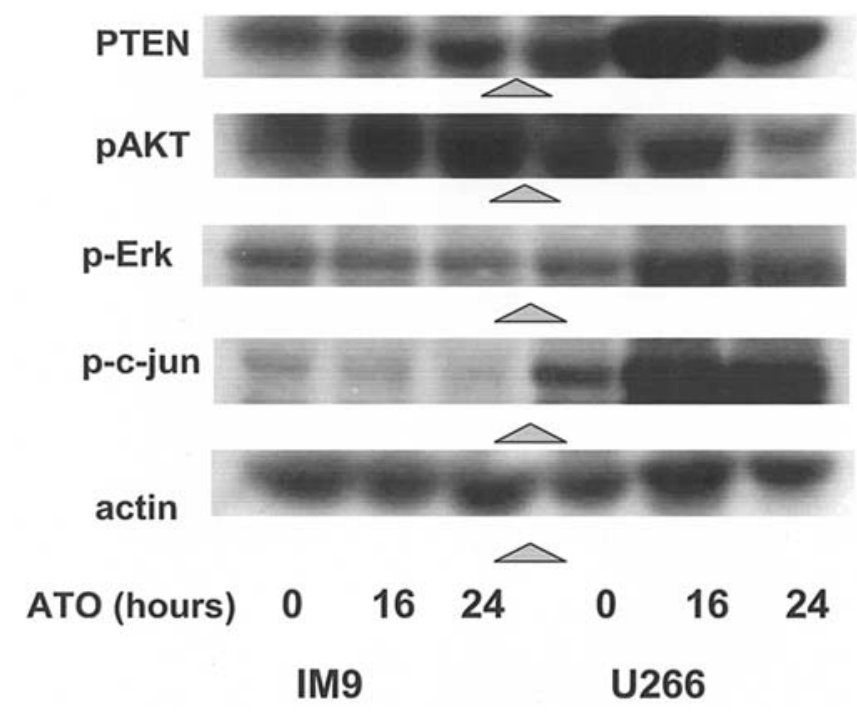

Figure 4. p53-dependent effect of ATO on PTEN, Akt, Erk and c-jun in IM9 and U266 cells. IM9 (w.t. p53) and U266 (mutant p53) cells were cultured for up to $24 \mathrm{~h}$ with $4 \mu \mathrm{M}$ of ATO. Fifty $\mu \mathrm{g}$ of protein was loaded onto each lane and SDS-PAGE and immunoblotting was performed as described in Materials and methods. Blots were probed for PTEN, p-jun, pErk and p-Akt. For loading controls, membranes were stripped and reprobed for $\beta$-actin. Note rapid increase in the levels of PTEN concomitant with rapid dephosphorylation of p-Akt in U266 cells compared to IM9 cells. In contrast, c-jun and Erk were rapidly activated in U266, but not in IM9 cells. Results from one representative experiment of 3 are shown.

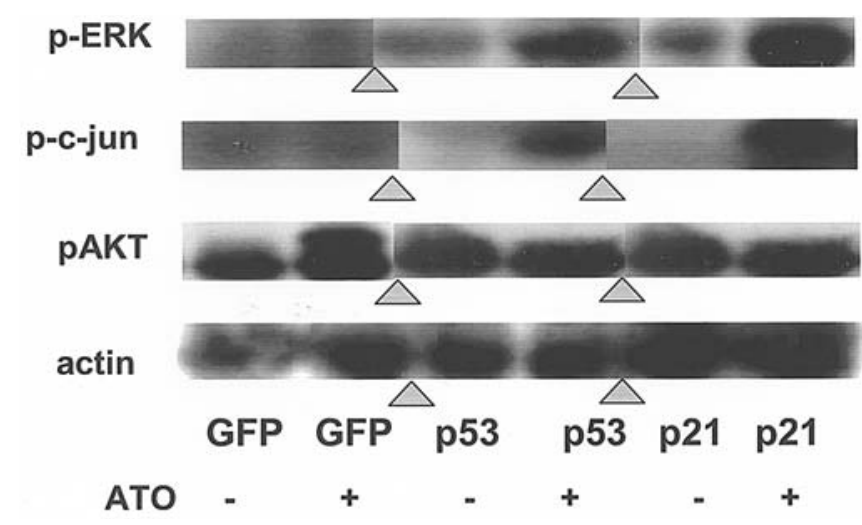

Figure 5. Effect of silencing of p21 or p53 on ATO-induced changes in the activation of Erk, c-jun and pAkt in $\mathrm{GFP}^{+}$-sorted IM9 cells treated with ATO. IM9 cells were nucleoporated and further cultured for $4 \mathrm{~h}$ to allow expression of SiRNAs. Cells were sorted for $\mathrm{GFP}^{+}$cells $(>90 \%)$ and sorted cells were then treated for $16 \mathrm{~h}$ with $4 \mu \mathrm{M}$ of ATO and total cell proteins were extracted and resolved on SDS-PAGE (41). Fifty $\mu \mathrm{g}$ of protein were loaded onto each lane. Proteins were transferred to a PVD nylon membrane and probed for cytochrome $\mathrm{c}$ and AIF. For loading controls, membranes were stripped and reprobed for $\beta$-actin. Results from one representative experiment of 3 are shown. Blots were probed for p-jun, pErk and pAkt. For loading controls, membranes were stripped and reprobed for $\beta$-actin. Note rapid activation of c-jun and Erk in p53 or p21 silenced IM 9 cells compared to GFP-empty vector controls. Results are in agreement with the results obtained from comparing cells expressing w.t. p53 (IM9) to cells expressing mutant p53 (U266) (Fig. 5 compared to Fig. 4).

We first studied whether p53 is differentially involved in the activation of c-jun, Erk, Akt and PTEN in cells expressing w.t. p53 (IM9) or mutant p53 (U266). Cells were treated with $4 \mu \mathrm{M}$ of ATO for up to $16 \mathrm{~h}$. The results of Western immuno- blotting depicted in Fig. 4 indicate a time-dependent phosphorylation of c-jun and Erk in U266 cells (mutant p53) with little activation of c-jun and Erk in IM9 cells (w.t. p53). In contrast to Erk and c-jun, Akt was phosphorylated in IM9 cells, but dephosphorylated in U266 cells treated with ATO. Of note is the observation that concomitant with dephosphorylation of Akt in U266 cells expressing mutant p53 the levels of PTEN, the phosphatases that control phosphorylation of Akt, increased (59).

Based on the results obtained above we hypothesized that silencing of p53 or p21 will result in differential activation of the MAP kinase pathway induced by treatment with ATO. IM9 cells were transfected with SiRNA for p21 and p53 and cultured for $4 \mathrm{~h}$ to allow optimal expression of SiRNA and downregulation of the corresponding proteins. Cells were treated with $4 \mu \mathrm{M}$ of ATO for $16 \mathrm{~h}$. The results of Western immunoblotting of these experiments, summarized in Fig. 5, indicate rapid activation of c-jun and Erk in p53 or p21 silenced IM 9 cells compared to GFP-empty vector controls, in agreement with the results obtained from comparing cells expressing w.t p53 (IM9) to cells expressing mutant p53 (U266) (Fig. 4 compared to Fig. 5). Similar to the results obtained by comparing U266 to IM9 cells (Fig. 4) we observed dephosphorylation of pAkt in p21 or p53 silenced cells compared to GFP-empty vector controls. These combined results clearly indicate that the differential effect of ATO depended on p53 function in the cells.

Effect of silencing of p53 on the expression of surface APO2/ TRAIL and APO2/TRAIL receptor-2. In previous studies we have shown that treatment with ATO of myeloma cells expressing mutant $\mathrm{p} 53$ resulted with increased expression of APO2/TRAIL and APO2/TRAIL receptor-2 compared to cells expressing w.t. p53, where only APO2/TRAIL receptor-2 was upregulated $(41,55)$. We, therefore, hypothesized that silencing of p53 will result in an increase in the expression of both, APO2/TRAIL and APO2/TRAIL receptor-2. IM9 cells were transfected with SiRNA for p21 and p53 and cultured for $4 \mathrm{~h}$ to allow optimal expression of SiRNA and downregulation of the corresponding proteins. Cells were then treated with up to $4 \mu \mathrm{M}$ of ATO for $16 \mathrm{~h}$ and were assayed for APO2/TRAIL and APO2/TRAIL receptor-2. The results obtained from 3 independent experiments support our hypothesis. Silencing of p53 in IM9 cells resulted in upregulation of both APO2/TRAIL (Fig. 6A) and APO2/ TRAIL receptor-2 (Fig. 6B). Upregulation of $10-41 \%$ and $11-56 \%$ was observed for APO2/TRAIL and APO2/TRAIL receptor-2, respectively at 2 and $4 \mu \mathrm{M}$ of ATO.

These combined results from the use of the SiRNA for silencing of p53 and p21 in w.t. p53 expressing cells, further support our p53 model for the role of p53 in ATO-induced apoptosis in myeloma and other cancer cell types $(41,58)$.

\section{Discussion}

In previous studies we have shown that ATO induces apoptosis in myeloma cells in two different mechanisms depending on p53 status in the cell. In myeloma cells expressing mutant p53, ATO induced extensive apoptosis mainly through the extrinsic apoptotic pathway by upregulating APO2/TRAIL 

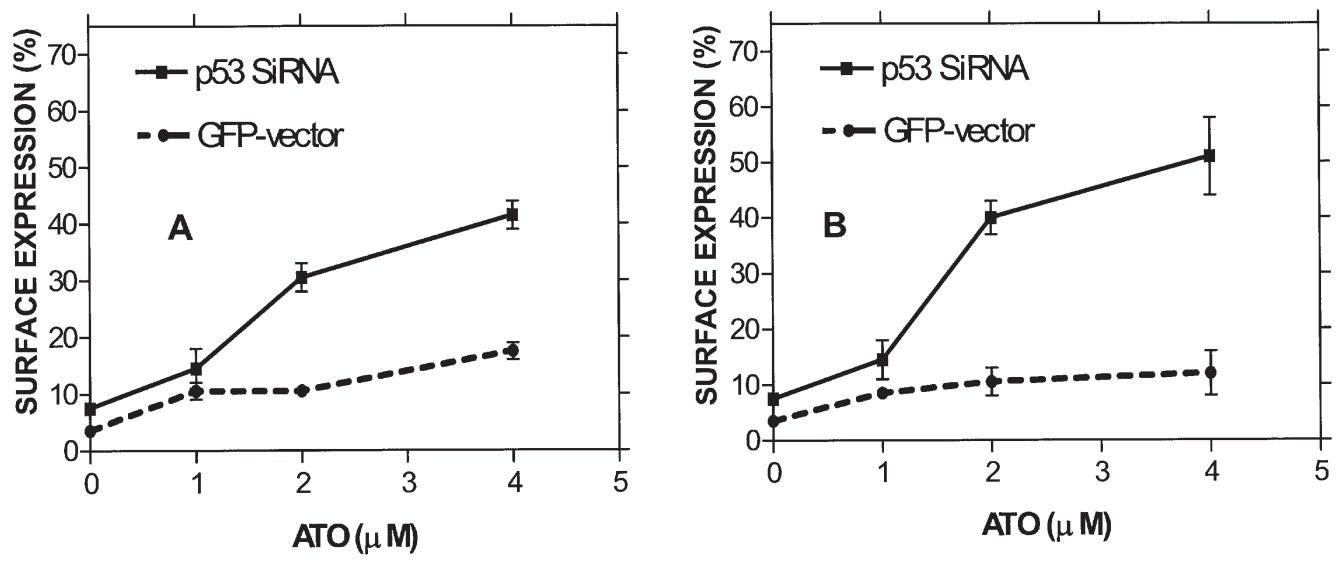

Figure 6. Effect of silencing of p21 or p53 on the expression of surface APO2/TRAIL (A) and APO2/TRAIL receptor-2 (B) in GFP ${ }^{+}$-sorted IM9 cells treated with ATO. IM9 cells were nucleoporated and further cultured for $4 \mathrm{~h}$ to allow expression of SiRNAs. Cells were treated for $16 \mathrm{~h}$ with $0-4 \mu \mathrm{M}$ of ATO, stained for APO2/TRAIL and for APO2/TRAIL receptor-2 and analyzed by flow cytometry as described in Materials and methods. Twenty thousand cells were analyzed. The results from 2 experiments are shown. Note enhanced upregulation of APO2/TRAIL and APO2/TRAIL receptor-2 in SiRNA silenced cells compared to GFP-control cells.

and APO2/TRAIL receptor-2 concomitant with activation of BID; early depolarization of mitochondrial membrane and release of AIF from mitochondria, which then translocates to the nucleus. In these cells ATO induced cell cycle arrest at $\mathrm{G} 2 / \mathrm{M}$ and apoptosis in prometaphase cells $(41,55)$. In contrast, cells expressing w.t. p53 were relatively resistant to ATO, and ATO blocked cell cycle at G1 through activation of p21. Mitochondrial membrane depolarization was slower and primarily cytochrome $\mathrm{c}$ was released from mitochondria concomitant with activation of caspase- 9 and thus engaging primarily the intrinsic mitochondrial pathway $(41,55)$.

One could argue that other characteristics of myeloma cells, besides p53 status, including variations in the levels of anti-apoptotic proteins and/or differences in the uptake of ATO by the ATO-designated transporter (56) account for the observed differences between these 2 types of myeloma cells and not p53 status per se. In the present study, we presented evidence that silencing of $\mathrm{p} 53$ or $\mathrm{p} 21$ resulted in a shift from the intrinsic to the extrinsic apoptotic pathway in response to ATO concomitant with increased apoptosis and mitochondrial membrane depolarization, marked decrease in the levels of reduced glutathione and increased activation of the MAP kinase pathway in response to ATO.

We and others (reviewed in ref. 57) have established that reactive oxygen specious (ROS) are generated early by ATO in various cell types. On the other hand, it has been reported that ROS can induce activation of stress kinases (SAPK), Erk and Akt $(61,62)$. Generation of ROS and activation of Akt have been reported for ATO-induced apoptosis in the U937 monocytic leukemia cell line (60). However, we demonstrate here, for the first time that silencing of p53 or p21 results in a rapid and extensive activation of c-jun and Erk and in dephosphorylation of Akt, and upregulation of PTEN, the phosphatases that regulate activation of Akt (59). Our results are consistent with those in myeloma cell lines expressing w.t. vs. mutant p53 (Fig. 4) and in IM9 cells following silencing of p53 or p21 (Fig. 5).

In the present study, we also presented evidence that silencing of $\mathrm{p} 53$ or $\mathrm{p} 21$ results in an increase in ATO-induced upregulation of APO2/TRAIL receptor-2 in response to ATO consistent with our previous publication comparing cells expressing w.t. with mutant p53 $(41,42)$, suggesting that in the absence of functional p53 the APO2/TRAIL apoptotic pathway is engaged in response to ATO, corroborating our model for the role of p53 in ATO-induced apoptosis $(41,42,57)$.

These results, taken together, suggest that p53 accelerates ATO-induced oxidation of glutathione, in agreement with our observation using Global Gene Microarray that ATO induces a decrease in the expression of glutathione reductase in IM9 cells expressing w.t. p53 (Gazitt Y and Akay C, 96 Proc Am Assoc Cancer Res: abs. 5380, 2005).

In light of the data presented here and in our previous studies, it is clear that prescreening of myeloma patients for p53 function could improve the response to treatment with ATO in addition to the use of drug combinations to improve the efficacy of ATO.

\section{Acknowledgements}

We would like to thank Mr. Charles Thomas for performing the flow cytometry at the Institutional/SACI Flow Cytometry Core Facility.

\section{References}

1. Vogelstein B and Kinzler KW: p53 function and dysfunction. Cell 70: 523-526, 1992.

2. Vogelstein B, Lane D and Levine AJ: Surfing the p53 network. Nature 408: 307-310, 2000.

3. El-Deiry WS: Regulation of p53 downstream genes. Semin Cancer Biol 8: 345-357, 1998.

4. Amundson SA, Myers TG and Fornace AJ Jr: Roles for p53 in growth arrest and apoptosis: putting on the brakes after genotoxic stress. Oncogene 17: 3287-3299, 1998.

5. Jõers A, Jaks V, Kase J and Maimets T: p53-dependent transcription can exhibit both on/off and graded response after genotoxic stress. Oncogene 23: 6175-6185, 2004.

6. Woods DB and Vousden KH: Regulation of p53 function. Exp Cell Res 264: 56-66, 2001.

7. Bargonetti J and Manfredi JJ: Multiple roles of the tumor suppressor p53. Curr Opin Oncol 14: 86-91, 2002.

8. Moll UM and Zaika A: Nuclear and mitochondrial apoptotic pathways of p53. FEBS Lett 493: 65-69, 2001.

9. Schuler M and Green DR: Mechanisms of p53-dependent apoptosis. Biochem Soc Trans 29: 684-688, 2002. 
10. Henry H, Thomas A, Shen Y and White E: Regulation of the mitochondrial checkpoint in p53-mediated apoptosis confers resistance to cell death. Oncogene 21:748-760, 2002.

11. Du C, Fang M, Li Y, Li L and Wang X: Smac, a mitochondrial protein that promotes cytochrome c-dependent caspase activation by eliminating IAP inhibition. Cell 102: 33-42, 2000.

12. Saelens X, Festjens N, Vande Walle L, van Gurp M, van Loo G and Vandenabeele P: Toxic proteins released from mitochondria in cell death. Oncogene 23: 2861-2867, 2004.

13. Jiang X, Wilford C, Duensing S, Munger K, Jones G and Jones D: Participation of survivin in mitotic and apoptotic activities of normal and tumor-derived cells. J Cell Biochem 83: 342-354, 2001.

14. Kawamura K, Sato N, Fukuda J, Kodama H, Kumagai J, Tanikawa H, Shimizu Y and Tanaka T: Survivin acts as an antiapoptotic factor during the development of mouse preimplantation embryos. Dev Biol 256: 331-341, 2003.

15. Roth W and Reed JC: Apoptosis and cancer: when BAX is TRAILing away. Nat Med 8: 216-218, 2002

16. Sax JK, Fei P, Murphy ME, Bernhard E, Korsmeyer SJ and El-Deiry WS: BID regulation by p53 contributes to chemosensitivity. Nat Cell Biol 4: 842-849, 2002.

17. Soignet SL, Maslak P, Wang ZG, Jhanwar S, Calleja E, Dardashti LJ, Corso D, De Blasio A, Gabrilove J, Scheinberg DA, Pandolfi PP and Warrell RP Jr: Complete remission after treatment of acute promyelocytic leukemia with arsenic trioxide. N Engl J Med 339: 1341-1348, 1998.

18. Hu J, Shen ZX, Sun GL, Chen SJ, Wang ZY and Chen Z: Longterm survival and prognostic study in acute promyelocytic leukemia treated with all-trans-retinoic acid, chemotherapy, and As2O3: an experience of 120 patients at a single institution. Int J Hematol 70: 248-260, 1999.

19. Jiang XH, Wong BC, Yuen ST, Jiang SH, Cho $\mathrm{CH}$, Lai KC, Lin MC, Kung HF and Lam SK: Arsenic trioxide induces apoptosis in human gastric cancer cells through upregulation of p53 and activation of caspase-3. Int J Cancer 93: 916-920, 2001.

20. Kinjo K, Kizaki M, Muto A, Fukuchi Y, Umezawa A, Yamato K, Nishihara T, Hata J, Ito M, Ueyama Y and Ikeda Y: Arsenic trioxide (As2O3)-induced apoptosis and differentiation in retinoic acid-resistant acute promyelocytic leukemia model in hGMCSF-producing transgenic SCID mice. Leukemia 14: 431-438, 2000.

21. Kitamura K, Minami Y, Yamamoto K, Akao Y, Kiyoi H, Saito H and Naoe T: Involvement of CD95-independent caspase 8 activation in arsenic trioxide-induced apoptosis. Leukemia 14: 1743-1750, 2000.

22. Park WH, Seol JG, Kim ES, Hyun JM, Jung CW, Lee CC, Kim BK and Lee YY: Arsenic trioxide-mediated growth inhibition in MC/CAR myeloma cells via cell cycle arrest and induction of cyclin-dependent kinase inhibitor, p21, and apoptosis. Cancer Res 60: 3065-3071, 2000.

23. Park JW, Choi YJ, Jang MA, Baek SH, Lim JH, Passaniti T and Kwon TK: Arsenic trioxide induces G2/M growth arrest and apoptosis after caspase- 3 activation and bcl-2 phosphorylation in promonocytic U937 cells. Biochem Biophys Res Commun 286: 726-734, 2001

24. Rego EM, He LZ, Warrell RP Jr, Wang ZG and Pandolfi PP: Retinoic acid (RA) and As2O3 treatment in transgenic models of acute promyelocytic leukemia (APL) unravel the distinct nature of the leukemogenic process induced by the PML-RARalpha and PLZF-RARalpha oncoproteins. Proc Natl Acad Sci USA 97: 10173-10178, 2000.

25. Park WH, Seol JG, Kim ES, Binderup L, Koeffler HP, Kim BK and Lee YY: Potential role of caspase-3 and -9 in arsenic trioxide-mediated apoptosis in PCI-1 head and neck cancer cells. Int J Oncol 18: 249-255, 2001.

26. Shen ZY, Shen J, Cai WJ, Hong C and Zheng MH: The alteration of mitochondria is an early event of arsenic trioxide induced apoptosis in esophageal carcinoma cells. Int J Mol Med 5: 155-158, 2000.

27. Shen ZY, Shen J, Li QS, Chen CY, Chen JY and Yi Z: Morphological and functional changes of mitochondria in apoptotic esophageal carcinoma cells induced by arsenic trioxide. World J Gastroenterol 8: 31-35, 2002

28. Shen ZY, Shen WY, Chen MH, Shen J, Cai WJ and Zeng Y: Mitochondria, calcium and nitric oxide in the apoptotic pathway of esophageal carcinoma cells induced by As2O3. Int J Mol Med 9: 385-390, 2002.

29. Warrell RP Jr: Arsenicals and inhibitors of histone deacetylase as anticancer therapy. Haematologica 84: 75-77, 1999.
30. Zhang TC, Cao EH, Li JF, Ma W and Qin JF: Induction of apoptosis and inhibition of human gastric cancer MGC-803 cell growth by arsenic trioxide. Eur J Cancer 35: 1258-1263, 1999.

31. Ora I, Bondesson L, Jonsson C, Ljungberg J, Porn-Ares I, Garwicz S and Pahlman S: Arsenic trioxide inhibits neuroblastoma growth in vivo and promotes apoptotic cell death in vitro. Biochem Biophys Res Commun 277: 179-185, 2000.

32. Akao Y, Nakagawa Y and Akiyama K: Arsenic trioxide induces apoptosis in neuroblastoma cell lines through the activation of caspase 3 in vitro. FEBS Lett 455: 59-62, 1999.

33. Larochette N, Decaudin D, Jacotot E, Brenner C, Marzo I, Susin SA, Zamzami N, Xie Z, Reed J and Kroemer G: Arsenite induces apoptosis via a direct effect on the mitochondrial permeability transition pore. Exp Cell Res 249: 413-421, 1999.

34. Dai J, Weinberg RS, Waxman S and Jing Y: Malignant cells can be sensitized to undergo growth inhibition and apoptosis by arsenic trioxide through modulation of the glutathione redox system. Blood 93: 268-277, 1999.

35. Davison K, Mann KK and Miller WH Jr: Arsenic trioxide: mechanisms of action. Semin Hematol 39: 3-7, 2002.

36. Bahlis NJ, McCafferty-Grad J, Jordan-McMurry I, Neil J, Reis I, Kharfan-Dabaja M, Eckman J, Goodman M, Fernandez HF, Boise LH and Lee KP: Feasibility and correlates of arsenic trioxide combined with ascorbic acid-mediated depletion of intracellular glutathione for the treatment of relapsed/refractory multiple myeloma. Clin Cancer Res 8: 3658-3668, 2002.

37. Choi YJ, Park JW, Suh SI, Mun KC, Bae JH, Song DK, Kim SP and Kwon TK: Arsenic trioxide-induced apoptosis in U937 cells involve generation of reactive oxygen species and inhibition of Akt. Int J Oncol 21: 603-610, 2002.

38. Jing Y, Dai J, Chalmers-Redman RM, Tatton WG and Waxman S: Arsenic trioxide selectively induces acute promyelocytic leukemia cell apoptosis via a hydrogen peroxide-dependent pathway. Blood 94: 2102-2111, 1999

39. Gartenhaus RB, Prachand SN, Paniaqua M, Li Y and Gordon LI: Arsenic trioxide cytotoxicity in steroid and chemotherapy-resistant myeloma cell lines: enhancement of apoptosis by manipulation of cellular redox state. Clin Cancer Res 8: 566-572, 2002.

40. Woo SH, Park IC, Park MJ, Lee HC, Lee SJ, Chun YJ, Lee SH, Hong SI and Rhee CH: Arsenic trioxide induces apoptosis through a reactive oxygen species-dependent pathway and loss of mitochondrial membrane potential in HeLa cells. Int J Oncol 21: $57-63,2002$

41. Akay C and Gazitt Y: Arsenic trioxide selectively induces early and extensive apoptosis via the APO2/caspase- 8 pathway engaging the mitochondrial pathway in myeloma cells with mutant p53. Cell Cycle 2: 358-368, 2003.

42. Akay C, Thomas C III and Gazitt Y: Arsenic trioxide and paclitaxel induce apoptosis by different mechanism. Cell Cycle 3: 324-334, 2004

43. Cai X, Yu Y, Huang Y, Zhang L, Jia PM, Zhao Q, Chen Z, Tong JH, Dai W and Chen GQ: Arsenic trioxide-induced mitotic arrest and apoptosis in acute promyelocytic leukemia cells. Leukemia 17: 1333-1337, 2003.

44. Platanias LC: Map kinase signaling pathways and hematologic malignancies. Blood 101: 4667-4679, 2003.

45. Shim MJ, Kim HJ, Yang SJ, Lee IS, Choi HI and Kim T: Arsenic trioxide induces apoptosis in CML K562 cells: possible involvement of p38 MAP kinase. J Biochem Mol Biol 35: 377-383, 2002.

46. Iwama K, Nakajo S, Aiuchi T and Nakaya K: Apoptosis induced by arsenic trioxide in leukemia U937 cells is dependent on activation of $\mathrm{p} 38$, inactivation of ERK and the $\mathrm{Ca}^{2+}$-dependent production of superoxide. Int J Cancer 92: 518-526, 2001.

47. Kroemer G and Reed JC: Mitochondrial control of cell death. Nat Med 6: 513-519, 2000.

48. Green DR and Kroemer G: The central executioner of apoptosis: mitochondria or caspases? Trends Cell Biol 8: 267-271, 1998.

49. Budihardjo I, Oliver H, Lutter M, Luo X and Wang X: Biochemical pathways of caspase activation during apoptosis. Ann Rev Cell Dev Biol 15: 269-290, 1999.

50. Susin SA, Daugas E, Ravagnan L, Samejima K, Zamzami N, Loeffler M, Costantini P, Ferri KF, Irinopoulou T, Prevost MC, Brothers G, Mak TW, et al: Two distinct pathways leading to nuclear apoptosis. J Exp Med 192: 571-580, 2000.

51. Cande C, Cecconi F, Dessen P and Kroemer G: Apoptosisinducing factor (AIF): key to the conserved caspase-independent pathways of cell death? J Cell Sci 115: 4727-4734, 2002.

52. Wang X, Yang C, Chai J, Shi Y and Xue D: Mechanisms of AIF-mediated apoptotic DNA degradation in Caenorhabditis elegans. Science 298: 1587-1592, 2002. 
53. Ye H, Cande C, Stephanou NC, Jiang S, Gurbuxani S, Larochette N, Daugas E, Garrido C, Kroemer G and Wu H: DNA binding is required for the apoptogenic action of apoptosis inducing factor. Nat Struct Biol 9: 680-684, 2002.

54. Lipton SA and Bossy-Wetzel E: Dueling activities of AIF in cell death versus survival: DNA binding and redox activity. Cell 111: 147-150, 2002.

55. Liu Q, Hilsenbeck S and Gazitt Y: Arsenic trioxide-induced apoptosis in myeloma cells: p53-dependent G1 or G2/M cell cycle arrest, activation of caspase 8 or caspase 9 and synergy with APO2/TRAIL. Blood 101: 4078-4087, 2003.

56. Liu Z, Shen J, Carbrey JM, Mukhopadhyay R, Agre P and Rosen BP: Arsenite transport by mammalian aquaglyceroporins AQP7 and AQP9. Proc Natl Acad Sci USA 99: 6053-6058, 2002.

57. Gazitt $Y$ and Akay C: Arsenic trioxide: an anti cancer missile with multiple warheads. Hematology 10: 205-213, 2005.

58. Gazitt Y: TRAIL is a potent inducer of apoptosis in myeloma cells derived from multiple myeloma patients and it's not cytotoxic to hematopoietic stem cells. Leukemia 13: 1817-1824, 1999.
59. Mayo LD and Donner DB: The PTEN, Mdm2, p53 tumor suppressor-oncoprotein network. Trends Biochem Sci 27: 462-467, 2002.

60. Choi YJ, Park JW, Suh SI, Mun KC, Bae JH, Song DK, Kim SP and Kwon TK: Arsenic trioxide-induced apoptosis in U937 cells involve generation of reactive oxygen species and inhibition of Akt. Int J Oncol 21: 603-610, 2002.

61. Torres M and Forman HJ: Redox signaling and the MAP kinase pathways. Biofactors 17: 287-296, 2003.

62. Torres M: Mitogen-activated protein kinase pathways in redox signaling. Front Biosci 8: D369-D391, 2003.

63. Hedley DW and Chow S: Evaluation of methods for measuring cellular glutathione content using flow cytometry. Cytometry 15: 349-358, 1994.

64. Barhoumi R, Bailey RH and Burghart RC: Kinetic analysis of glutathione in anchored cells with monochlorobimane. Cytometry 19: 226-234, 1995. 